\title{
Baudelaire e a linguagem das Correspondências
}

Álvaro Cardoso Gomes ${ }^{1}$

RESUMO: Tendo como núcleo a análise de "Correspondances", de Baudelaire, este ensaio procura rastrear as origens das principais imagens místico-estéticas do poema. Numa segunda instância, procura determinar como as tendências místicas adquirem um viés estético no soneto, fazendo com que o poema se constitua numa espécie de profissão de fé do Simbolismo.

PALAVRAS-CHAVE: Correspondências, misticismo, Natureza, templo, estética, Simbolismo.

ABSTRACT: Through the analyses of Baudelaire's poem "Correspondances", this essay first tries to show the origins of the poem's main mystical images. Secondly, it tries to show how these images acquire aesthetic value, granting the sonnet the status of Symbolism's doctrinal statement. KEYWORDS: Correspondences, mysticism, Nature, temple, aesthetic, Symbolism.

\section{Uma experiência místico-esté tica}

O soneto "Correspondances" participa da estética/metafísica de Baudelaire de maneira muito especial, pois constitui a base de uma experiência alquímica, ou seja, o poema é um laboratório no qual uma experiência mística se transforma numa experiência estética. Baudelaire, com sua imaginação poderosa, aproveita-se das múltiplas influências do misticismo então em voga (Swedenborg, Fourier, Gal, Lavater, Saint-Martin. Oegger, Richer) para promover uma alteração fundamental no pensamento estético do tempo. $\mathrm{O}$ imagismo místico coloca-se a serviço da causa estética, como se a experiência do misticismo fosse semelhante à do trabalho alquímico (que, por sua vez é similar à do poético), pois nessas atividades sempre encontraremos a mesma tentativa de liberar a matéria bruta de impurezas. Essa similaridade vem expressa nos versos de "Ébauche d'un Epilogue":

O vous, soyez témoins que j’ai fait mon devoir Comme un parfait chimiste et comme une âme sainte (BAUDELAIRE, 1961, p. 220).

Mas vamos ao soneto:

La Nature est un temple où de vivants pilliers

Laissent parfois sortir de confuses paroles;

L'homme y passe à travers des forêts de symboles

Qui l'observent avec des regards familiers.

Comme de longs échos qui de loin se confondent

Dans une ténébreuse et profonde unité,

1 Professor Titular da Universidade de São Paulo e do Mestrado Multidisciplinar da Universidade de Santo Amaro (Unisa) - São Paulo. Também é ensaísta e romancista. 
Vaste comme la nuit et comme la clarté,

Les parfums, les couleurs et les sons se répondent.

Il est des parfums frais comme les chairs d'enfants,

Doux comme les hautbois, verts comme les praieries,

- Et d'autres, corrompus, riches et triomphants,

Ayant l'expansion des choses infinies,

Comme l'ambre, le musc, le benjoin et l'encens,

Qui chantent les transports de l'esprit et des sens.

(BAUDELAIRE, 1961, p. 13)

"Correspondances" seria, portanto, o que se pode chamar de um poema programático, na medida em que há nele uma espécie de ensinamento que, não sendo evidentemente nem moral, nem social ou político, é realizado de maneira cifrada, de modo a permitir que um iniciado tenha a oportunidade de cumprir tarefas ritualísticas (ligadas ao desenvolvimento dos sentidos) para alcançar a plenitude do "espírito e dos sentidos". Talvez devido a seu caráter programático, "Correspondances" seja um caso único na poesia baudelaireana, pois o que se propõe aqui, como a teoria das correspondências, dilui-se em Les fleurs du mal, a ponto de não mais ser tratado tão abertamente. Quando muito, três poemas aproximam-se um pouco da experiência ritualística de "Correspondances": "Élévation", que trata do desejo do poeta de elevar-se acima deste mundo inóspito para um espaço de pura abstração, onde pode compreender "sem esforço/A linguagem das flores e das coisas mudas!" e onde pode realizar a decifração da natureza, conforme os ensinamentos transmitidos em "Correspondances"; "La vie antérieure", que poetiza o prazer totalizador, sonhado pelo homem e indiciado pelo evangelho das correspondências e "Obsession", cujo primeiro verso - "Grandes bosques, vós me assustais como catedrais" - retoma a imagem do templo enunciada na abertura do famoso soneto. A referência explícita às correspondências comparece mais claramente ao longo da estética e da prosa poética baudelaireana.

\section{A origem do tema e das imagens de "Correspondances"}

São várias as origens do tema central e das imagens que comparecem em "Correspondances". Swedenborg é o primeiro grande nome que deve ser arrolado, devido ao tópico das correspondências que já aparece no título do poema. Emanuel Swedenborg, que nasceu em Estocolmo em 29 de janeiro de 1689, era um cientista já bastante conhecido por seus trabalhos na área da mineralogia, da Física etc. Em 1743, um acontecimento sobrenatural veio modificar radicalmente sua vida: o cientista sueco teve uma visão, em que um anjo the apareceu e the fez algumas revelações. Ao despertar, passou por um longo período em estado catatônico e só depois disso começou a divulgar a nova doutrina, a partir do que lhe fora ditado pelo anjo e do que ele próprio afirmou ter visto em seus sonhos místicos. De Coelo et de Inferno (1758) é sua obra mística mais conhe-
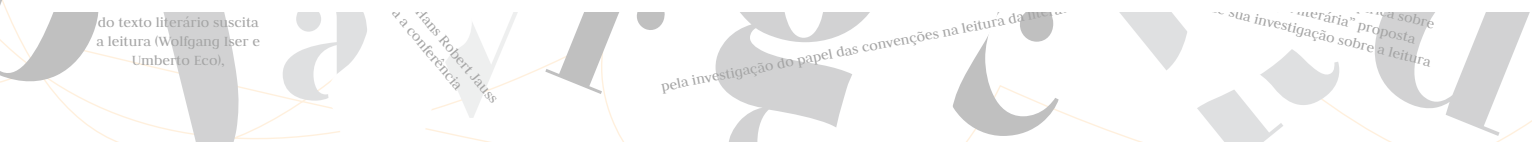
cida e a que exerceu maior influência sobre os românticos e simbolistas. Baseada nos Evangelhos, explica de maneira bastante minuciosa as íntimas relações entre os reinos do Céu e do Inferno e a Terra, considerada como o espaço onde o homem deve procurar a presença do Divino. A religião criada por Swedenborg é toda ela simétrica, ao estabelecer, de modo especular, as chamadas "correspondências" entre os diversos reinos. Embora o princípio de tudo seja a unidade, que é Deus, de onde provém o Divino, sua emanação, "que afeta os anjos e constitui o céu", o ponto de referência para o imagismo swedenborguiano é sempre o homem (que, por sua vez, é o reflexo do divino).

Swedenborg irá encantar os simbolistas pelo seu misticismo, por essa religião nascida de iluminações que dá um sentido simbólico, hieroglífico ao existente. Mas é preciso acentuar que o misticismo swedenborguiano vem de várias fontes e pode, inclusive, ser encontrada na famosa Tabula Smaragdina, a bíblia alquimista. O que Swedenborg fez foi sistematizar um velho pensamento e divulgá-lo em sua obra enciclopédica. Sobretudo, o que chama a atenção dos autores românticos e pós-românticos na obra do místico é mesmo a doutrina das "correspondências" que comparece na primeira parte do livro, de modo mais evidente entre os parágrafos 87 e 115 de dois subcapítulos, intitulados "Que há uma Correspondência de todas as coisas do Céu com todas as Coisas do Homem" e "Que há uma Correspondência do Céu com todas as Coisas da Terra".

O pensamento cifrado, hieroglífico de Swedenborg cobre três etapas de uma história em que as relações entre o Divino e o humano foram sofrendo um processo de deterioração, e tal processo de deterioração acaba por ser manifesto por meio de representações simbólicas. Tudo o que existe no mundo natural, sob o sol, tem um valor simbólico - explica Swedenborg -, no sentido de que as coisas materiais não valem por si próprias, ou seja, elas são homólogas às coisas que existem no mundo espiritual, de onde emanaram. O místico sueco concebe o Universo de modo especular: as correspondências seriam o elo entre as diferentes coisas do reino material, natural e as do reino espiritual. A razão para que haja a correspondência é que se uma coisa do mundo fosse separada de seu arquétipo, desapareceria, porque nada subsiste por si próprio e porque tudo é emanação de um primeiro Princípio, que é o Senhor. Portanto, se o homem ainda possuísse a ciência das correspondências, poderia interpretar o sentido enigmático das coisas do mundo natural e, a partir daí, entrar em contato com os Anjos, que são a manifestação primeira dos céus. Mas acontece que há uma segunda etapa nessa história mítica da humanidade. Para suprir a falta das correspondências, o Senhor deu ao homem a Palavra que, de modo idêntico às coisas que mantêm correspondência entre si, tem um sentido interno ou espiritual e outro material. É através da interpretação do sentido espiritual da Palavra (isto é, a Palavra jamais deve ser entendida ao pé da letra) que o homem vem a ter de novo acesso ao universo das correspondências, à linguagem dos Anjos. Swedenborg toca aqui no problema do símbolo, porquanto a Palavra a que se refere é aquela conotativa, capaz de sugerir o mundo das correspondências. Mas essa não é uma verdade demonstrada cientificamente - daí vem o princípio de que tudo é hieroglífico, ideia que remete à metáfora das "florestas de símbolos" de "Correspondances".

Quanto às imagens, lembro aqui Chateaubriand, um escritor que utilizou algumas muito semelhantes às que Baudelaire, anos mais tarde, utilizaria em seu soneto. Ao 
tratar das igrejas góticas, em Le génie du Christianisme, o poeta francês usa de um metaforismo retirado em grande parte da Natureza:

Essas abóbodas cinzeladas em folhagens, esses pilares, que apóiam as paredes e terminam bruscamente como troncos cortados, a frescura das abóbodas, as trevas dos santuários, as alas obscuras, as passagens secretas, as portas baixas, tudo lembra os labirintos dos bosques na igreja gótica [...]. Mesmo os pássaros parecem se enganar, adotando-as como as árvores de suas florestas; as cornijas volteiam em torno de seus cimos e se empoleiram sobre suas galerias. Mas de repente rumores confusos escapam do cimo dessas torres e expulsam delas os pássaros amedrontados. A arquitetura cristã, não contente em edificar florestas, quis, por assim dizer, imitar-lhes os murmúrios! e, por meio do órgão e o bronze suspenso, destinou ao templo gótico até o ruído dos ventos e das tempestades, que rolam na profundeza dos bosques. (CHATEAUBRIAND, 1885, p. 45)

Primeiro, há a aproximação da igreja gótica de uma floresta; depois, a referência aos pilares, que se assemelham a "troncos cortados"; em seguida, a menção dos "rumores confusos", que escapam do meio das torres. O paralelismo com "Correspondances" parece bem claro, embora o ponto de partida analógico esteja invertido: em Chateaubriand, o templo é que se assemelha a uma floresta; em Baudelaire, a Natureza, pelo contrário, é similar a um templo. Também os "pilares", que "terminam bruscamente como troncos cortados", e os "rumores confusos" e "murmúrios" que saem da igreja gótica lembram os "vivos pilares" e as "confusas palavras" do soneto baudelaireano.

Em Hoffmann, é possível encontrar a referência ao uso das sinestesias, à fusão dos mais diversos sentidos, nesta citação que Baudelaire faz do escritor alemão no "Salon de 1846":

\footnotetext{
Não é somente no sonho e no ligeiro delírio que precede ao sono; é ainda acordado, quando ouço música, que encontro uma analogia e uma reunião íntima entre as cores, os sons e os perfumes. Me parece que todas essas coisas foram engendradas por um mesmo raio de luz e que elas devem-se reunir num maravilhoso concerto. O odor das inquietações escuras ou rubras produz sobretudo um efeito mágico sobre minha pessoa. Ele me faz cair num devaneio profundo, e ouço agora como de longe os sons graves e profundos dos oboés. (BAUDELAIRE, 1962, p. 109)
}

"As cores, os sons e os perfumes" têm relação com "os perfumes, as cores e os sons" do soneto, e o mesmo se pode dizer dos oboés que comparecem no primeiro terceto de "Correspondances".

Em Lamartine, a imagem explícita da natureza metaforizada como um templo comparece no poema "L'imortalité". Salienta-se também a ideia de que há um espírito que espia o homem contemplador:

Dieu caché, disais-tu, la nature est ton temple!

L'esprit te voit partout quand notre oeil la contemple;
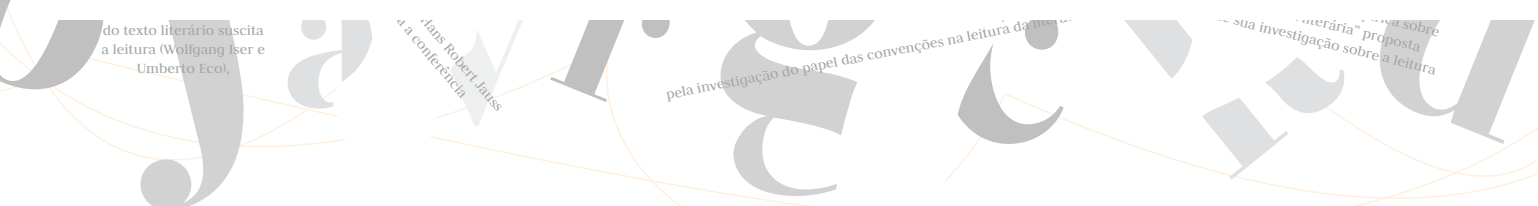
De tes perfections, qu'il cherche à concevoir,

Ce monde est le reflet, l'image, miroir; (LAMARTINE, 1963, p. 17-18)

Edgar Allan Poe, no poema "Al Aaraaf" - "All Nature speaks and even ideal things/ Flap shadowy sounds from visionary wings..." (POE, 1938, p. 932) -, trata da natureza que fala ao homem. A linguagem da Natureza, explícita no poeta americano, vem apenas sugerida em "Correspondances": em meio à floresta de símbolos, nascem confusas palavras. Também o adjetivo "sombrio" é relevante, na medida em que sugestivamente nos remete ao "tenebroso" mundo evocado no soneto.

Mas, de todos os escritores, quem impressionou Baudelaire de maneira mais radical talvez tenha sido Balzac, seja no plano da teoria, seja no plano das imagens. Para Mansell Jones, "a evidência parece favorecer o ponto de vista de que foi Honoré de Balzac quem providenciou, senão o primeiro palpite, pelo menos o principal estímulo para o interesse de Baudelaire por Swedenborg" (MANSELL JONES, 1951, p. 11). Mais conhecido como escritor romântico-realista, cronista de costumes, Balzac, em determinado momento da existência, teve suas visões, provocadas por leituras desordenadas de Jacob Bohëm, Swedenborg, Saint-Martin, Mme. Guyon e principalmente Lavater. Resultaram dessa sua experiência mística a obra Livre mystique, contendo o conto "Les proscrits", e os romances Louis Lambert, Séraphita (1832) e Les lys dans la valée (1835). Em Séraphita, num determinado momento, a personagem, em êxtase, resume as teorias swedenborguianas, sobretudo às relativas ao evangelho das correspondências:

Vosso invisível universo moral e vosso visível universo constituem uma só e mesma matéria [...]. Para saber o verdadeiro sentido das leis fenomênicas não seria necessário conhecer as correlações que existem entre os fenômenos e a lei do conjunto? (BALZAC, 1966, p. 50)

O swedenborguismo, por conseguinte, manifesta-se em Balzac na referência explícita ao mestre sueco e nas personagens, concebidas como seres exilados na Terra e que, possuídas por uma loucura visionária, interpretam os sinais de uma linguagem inacessível ao comum dos mortais. Baudelaire conhecia bastante bem as obras místicas de Balzac, a ponto de considerá-lo um "iluminado" e a ponto de seguir-lhe os passos, no que diz respeito a uma iniciação mística, a responsável, quem sabe, por certas concepções e imagens presentes em “Correspondances”. Quanto às imagens, encontramos em Balzac uma aproximação entre a Natureza e os templos, quiçá inspirado por Chateaubriand:

Seja uma longa aleia de floresta semelhante a qualquer nave de catedral, onde as árvores são pilares, onde seus ramos formam os arcos da abóboda, ao fim do qual, uma clareira longínqua, nos dias mesclados de sombras ou matizados pelas tintas vermelhas do poente, desponta através das folhas e se mostra como os vitrais coloridos de um coração cheio de pássaros que cantam. (BALZAC, 1966, p. 329)

O transcendentalista norte-americano Ralph Waldo Emerson pode ser evocado também como um dos autores que tratam de tópicos semelhantes ao do poema de $\mathrm{Bau}^{-}$
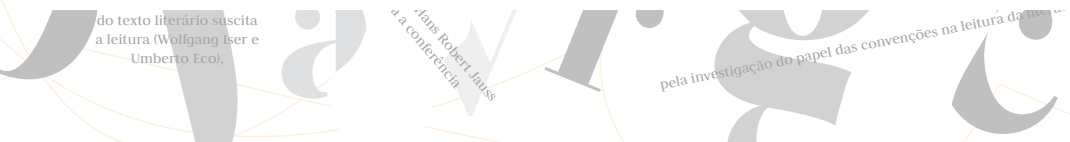
delaire, sobretudo, se cotejarmos este fragmento do seu ensaio "Nature" com o primeiro quarteto de "Correspondances": "O maior prazer que os campos e florestas ministram é a sugestão de uma oculta relação entre o homem e o vegetal. Não estou sozinho e nem sou desconhecido. Eles acenam para mim e eu para eles" (EMERSON, 1968, p. 7).

A ideia desenvolvida por Emerson de que a Natureza ama o homem e o reconhece como igual a si tem seu paralelo nos versos em que Baudelaire diz que o homem passa pelas florestas de símbolos que lhe lançam "olhares familiares".

Outras similaridades importantes podem ser encontradas entre imagens do soneto de Baudelaire e as de poemas de Abée Constant (que depois adotaria o nome místico de Eliphas Lévi) e de Gérard Nerval. Do primeiro, é o poema intitulado "Les correspondances", do livro Les trois harmonies:

\author{
Rien n'est muet dans la nature \\ Pour qui sait en suivre les lois: \\ Les astres ont une écriture, \\ Les fleurs des champs ont une voix, \\ Verbe éclatant dans les nuits sombres, \\ Mots rigoureux comme des nombres, \\ Voix dont tout bruit n’est qu'un écho. (apud BÉNICHOU, 1977, p. 437)
}

Além do título que Baudelaire utiliza apenas com a omissão do artigo, ainda é importante ressaltar os seguintes pontos: a) tudo fala na Natureza e o homem pode entender a linguagem natural desde que lhe entenda as leis; b) a oposição entre a luz e a trevas e c) a referência ao eco.

Quanto a Nerval, a influência vem do poema "Vers dorés":

Homme libre penseur! te crois-tu seul pensant

Dans ce monde ou la vie éclate en toute chose?

Des forces que tu tiens la liberté dispose,

Mais de tous tes conseils l'univers est absent.

Respect dans la bête un esprit agissant:

Chaque fleur est une âme à la Nature éclose;

Un mystère d'amour dans le métal répose;

“Tout est sensible!” Et tout sur ton être est puissant.

Crains, dans le mur aveugle, un regard t'épie:

A la matière même un verbe est attaché...

Ne la fais pas servir à quelque usage impie!

Souvent dans l'être obscur habite un Dieu caché;

Et comme un oeil naissent couvert par ses paupières,

Un pur sprit s'accroît sous l'écorce des pierres! (NERVAL, 1973, p. 54)

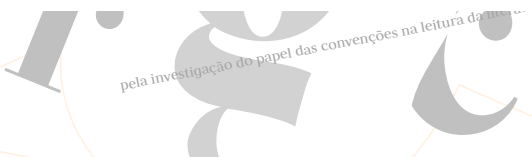


As similaridades aqui são mais sutis e fazem-se notar no sentido global do poema: há um espírito agregado às coisas que lança um olhar ao homem indiferente ao sentido anímico do Universo. Essas imagens remetem ao primeiro quarteto de "Correspondances", quando Baudelaire se refere aos "olhares familiares" que vêm das "florestas de símbolos". Ambos os poetas tratam da alienação do homem em relação à Natureza e da intensa vida espiritual, que se oculta sob as coisas materiais no Universo.

Em suma, as fontes onde Baudelaire talvez tenha bebido parecem se concentrar, numa primeira instância, na ideia basilar das correspondências, que provém de Swedenborg e dos seus discípulos. Em segundo lugar, na aproximação metafórica entre a Natureza e o templo (Chateaubriand, Lamartine, Balzac); em terceiro lugar, na referência a uma linguagem especial, sem palavras, que existe no seio da Natureza e precisa ser decifrada pelo homem (Poe, Emerson, Abée Constant, Nerval); em quarto lugar, na sugestão das correspondências entre os diversos sentidos (Hoffmann, Balzac); em quinto lugar, na referência à ideia de que a Natureza tem consciência da existência do homem e que procura acolhê-lo como um seu igual (Emerson, Nerval) e, em sexto lugar, no uso de certas palavras-chave, comuns à experiência de vários escritores: "natureza", "homem", "palavras", "símbolo", “correspondência” "floresta”, “templo", “pilares”, “cores”, "sons", “perfumes", “oboés”, "espiar ('observar')", "fresco”, "profundo”, “obscuro”, "confuso", "eco", "sombrio ('tenebrosa')".

Contudo, é preciso considerar o seguinte: se Baudelaire bebeu de várias fontes, o que é muito comum em se tratando de criação poética, não devemos nos esquecer de que ele imprimiu ao soneto vida própria. Assim, não é difícil determinar, em "Correspondances", uma específica visão de mundo que remete a uma também específica e muito pessoal teoria da arte. As influências místicas que provêm de Swedenborg, por exemplo, sofreram notável modificação nas mãos de Baudelaire. É o que Mansell Jones procura demonstrar ao apontar as diferenças substanciais entre o poeta e o místico:

O místico é preciso; o poeta impreciso. Um expõe; o outro sugere. Swedenborg está interessado em demonstrar o que tudo isso significa; Baudelaire está interessado no fenômeno da significação: o "celebrado" soneto é um dos mais importantes protótipos do introvertido, esotérico simbolismo a ser elaborado por Mallarmé. Há ainda mais um contraste específico a se notar. A linguagem de Swedenborg é bíblica e familiar. A de Baudelaire poderia ter sido familiar somente para os leitores de alguns de seus predecessores: Chateaubriand, Balzac, Nerval, Hoffmann ou mesmo o próprio Swedenborg. A linguagem do soneto já levou quase um século para ser explicada. (MANSELL JONES, 1951, p. 27, 28)

A diferença fundamental entre Baudelaire e os swdenborguianos reside no seguinte: Swedenborg e seguidores visavam a um fim místico e, como tal, procuravam fazer da linguagem apenas um instrumento para traduzir o mundo das correspondências. Daí a "precisão", a "familiaridade" da linguagem, a que Mansell Jones se refere. Baudelaire, ao contrário, evita instrumentalizar a linguagem; ou melhor, Baudelaire procura uma linguagem. O seu fim é encontrar um novo código que baste a si mesmo, que conserve todas as potencialidades de uma linguagem primitiva, tradutora do sentido do Cosmo.
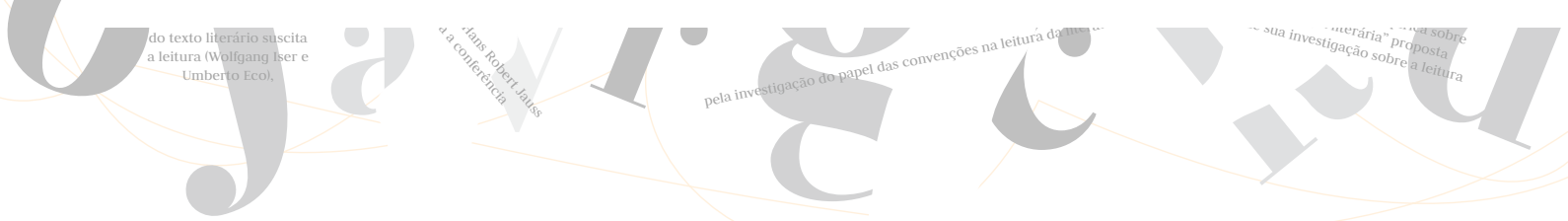
A “imprecisão" (a que se refere também Mansell Jones) é proposital, na medida em que a linguagem não é manipulada para traduzir um sentido, e sim sugerir um mundo original, onde as relações entre o ser e a Natureza se dão através das correspondências. Isso nos permite recordar aqui as palavras de Ana Balakian, que diz que Baudelaire promove uma reciclagem dos conceitos místicos de Swedenborg: "A sinestesia que se produz na mescla das percepções sensoriais não dá como resultado um vínculo entre céu e terra nem nos transporta ao estado divino, mas encontra suas conexões entre as experiências sensoriais aqui na terra" (BALAKIAN, 1969, p. 52).

Algo semelhante precisa ser dito a respeito dos poetas e prosadores pertencentes à faixa histórica que vai do Romantismo emergente ao Decadentismo/Simbolismo e que tratam do tema das correspondências e criam imagens acerca da similaridade entre o templo e a Natureza. Baudelaire como que conjuga em seu poema metáforas e símbolos de um mesmo dicionário imagético, pelo fato de que estava integrado com tais autores no que diz respeito a uma espécie de corrente espiritual em voga, a qual se servia, como em todas as tendências espirituais, de um mesmo vocabulário, digamos, técnico. Tais imagens e/ou tal vocabulário seriam como que símbolos encantatórios, comuns a qualquer experiência mística que Baudelaire necessariamente teria de repetir se quisesse participar da corrente espiritual de seu tempo. Essa linguagem caracterizada pela força evocadora das palavras seria equivalente ao mantra de um ritual cosmogônico, que, entoado, tem o poder de conduzir o ser ao tempo sagrado. Mas, se Baudelaire retoma um repertório linguístico, ao mesmo tempo, renova-o, reatualiza-o, ao expandi-lo com imagens que procuram integrar a experiência mística na experiência estética.

\section{Exegese de "Correspondances"}

O poema, em seu título, já oferece uma de suas chaves: Baudelaire tratará nele da correspondência entre as coisas. "A Natureza é um templo" - com o símile, o poeta revela que tudo é analógico. Mas é importante assinalar que, se a analogia determina a aproximação entre coisas díspares ("Natureza" e "templo"; "longos ecos" e "perfumes, cores, sons"; "perfumes frescos" e "carnes de crianças", "perfumes doces" e "oboés", "perfumes verdes" e "pradarias"; "a expansão das coisas infinitas" e "o âmbar, o almíscar, o benjoim e o incenso"), por outro lado, preserva a identidade dessas mesmas coisas. É o que Octavio Paz observa:

A analogia é a ciência das correspondências. Só que é uma ciência que não vive senão graças às diferenças: precisamente porque isto não é aquilo, é capaz de lançar uma ponte entre isto e aquilo. A ponte é a palavra como ou a palavra é: isto é como aquilo, isto é aquilo. A ponte não suprime a distância: é uma mediação; tampouco anula as diferenças: estabelece uma relação entre termos distintos. [...] Pela analogia, a paisagem confusa da pluralidade e da heterogeneidade ordena-se e torna-se inteligível; a analogia é a operação, por intermédio da qual, graças ao jogo das semelhanças, aceitamos as diferenças. A analogia não suprime as diferenças: redime-as, torna sua existência tolerável. (PAZ, 1984, p. 99) 
Assim, não é de estranhar que Baudelaire, à exceção de duas metáforas - "vivants piliers" e "forêts de symboles" -, utilize-se do símile que abre o poema e de uma profusão de comparações. A Natureza, sem perder suas prerrogativas de Natureza, é similar à construção erigida pelo homem, ou ainda, invertendo o símile, a construção erigida pelo homem tem similaridade com a Natureza, equivale a ela, constitui uma supranatureza, uma sublimação, dedicada tão só ao plano do espírito. Mas observe-se que o símile aproxima a Natureza de uma construção humana especial: o templo não tem utilidade alguma, é um edifício "gratuito", pois tem um sentido místico, serve para unir o profano ao sagrado, é o sinal de uma realidade transcendente, misteriosa. O templo é o local onde se celebram ritos, e sua construção, obedecendo a determinadas normas, visa a conformar a matéria ao espírito, ao sobrenatural. O edifício identifica-se com seu modelo primevo, a floresta. Como em Chateaubriand ou em Balzac, podemos dizer que as volutas dos arcos são ramos, que os pilares são troncos e que as ogivas são clareiras entre as árvores, por onde o sol filtra os raios, atenua a força da luz e vem banhar de cor os frescos pavimentos.

Quando Baudelaire inverte o símile, dizendo que a "Natureza é um templo" (em realidade, o templo que é Natureza, ou pelo menos, o templo imita a Natureza, pois os primeiros ritos do homem tiveram lugar no recesso de um bosque), é porque já está pensando numa natureza naturante em vez de uma natureza naturada, esta, passiva, aquela, a "eficiente Natureza [...], a rápida causa da qual todas as formas partem" (EMERSON, 1968, p. 410-411). A Natureza naturante é causa eficiente, é templo, porque, ao contrário da natureza passiva, objeto de decoração, vazio cenário, na frente do qual o homem representa uma comédia, é um livro a ser interpretado, no qual tudo está inextricavelmente ligado, tudo tem um significado.

Vem daí que, no mundo natural, as coisas sejam animadas de vida: as árvores transfiguram-se, assemelhando-se a pilares, mas pilares vivos, por onde, às vezes, escapam confusas palavras. Confusas, porque o homem que passa não as entende. Esse passante distraído é o ser alienado, que não tem acesso à realidade mágica e não sabe como ler o livro mágico da Natureza, pois ela é “o real em sua potência, capaz de um vir-a-ser. Esse real é ordenado a uma consciência inspirada" (DUFRENNE, 1969, p. 186-187). Todavia, se ao homem a linguagem das coisas é indecifrável, ou ainda, se o ritual desse templo não possui para ele sentido algum, o mesmo não se dá com a Natureza. Afinal, a Natureza olha para o homem com um olhar compassivo: as florestas de símbolos observam-no com “olhares familiares". Em suma, se o homem não está pronto para participar da Natureza, esta, pelo contrário, o reconhece como um seu igual.

O problema, então, está no homem, no pobre homem civilizado que sacrifica a experiência sensorial pelo constante exercício da reflexão. Enquanto os sentidos o auxiliariam a ter uma visão global da realidade, a razão, pelo contrário, implica uma atomização do Universo. Inicia-se aí um processo de fissura: essa Natureza apreendida racionalmente é parte sem um todo, e o homem que a contempla também não passa de uma parte isolada das demais, com o agravante de oferecer em si uma cisão interna entre um corpo que teoricamente deveria sentir e uma consciência que se analisa. Emerson observa que até que a razão intervenha, "o olho animal vê, com maravilhosa precisão, contornos agudos e superfícies coloridas [...]. Se a Razão é estimulada a uma
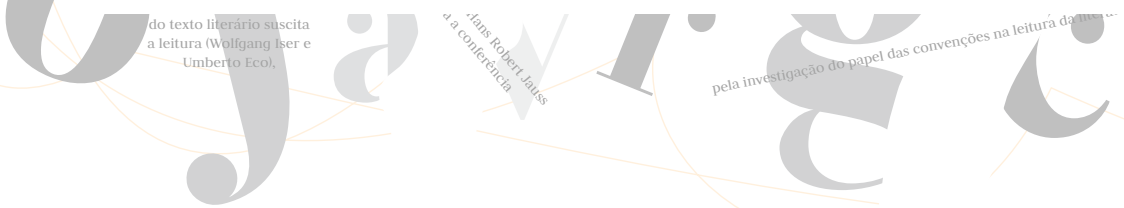
mais diligente visão, os contornos e as superfícies se tornam transparentes, e não são mais vistos" (EMERSON, 1968, p. 27).

A consequência da interferência cada vez maior da parte racional é que o corpo e a alma do ser se transformam em entidades autônomas, agindo por impulsos opostos e criando conflitos insolúveis. Os sentidos se especializam, ganham autonomia. É o que Saint Martin dá a entender, dizendo que, no homem,

\footnotetext{
todas as virtudes intelectuais, com as quais [...] devia agir de concerto e que deviam lhe apresentar uma unidade de ação, se encontram repartidas, separadas e fechadas em sua esfera e em sua região; de maneira que o que era simples e uno, para ele, transformou-se em múltiplo e dividido. (SAINT MARTIN, 1946, p. 67-68)
}

Preocupado em se autoconhecer e em apreender e dominar a Natureza, este ser desintegrado vê-se obrigado a reduzir o poder de sua parte sensorial, na medida em que a razão é mais do que suficiente para o domínio global do mundo exterior. Contudo, esse domínio é falacioso, em virtude do fato de que o seu domínio se exerce somente sobre projeções, simulacros degradados de um universo que perdeu a unidade.

Este ser que se desintegrou é similar ao signo instrumentalizado, em que significante e significado formam entidades autônomas. Na instrumentalização da linguagem, o signo deixa de ter valor em si: o significante é mero transporte para um significado desgastado, único, previsível. O mesmo não se dá com o símbolo ou com a palavra poética em geral: significante e significado são indissociáveis, e a relação que mantêm, por ser altamente motivada, implica a plurissignificação. O homem civilizado, que perdeu de vez o contato com a Natureza, assemelha-se ao primeiro tipo de signo: corpo e alma também são entidades autônomas. A alma despreza o corpo e anseia por espaços ideais, onde possa cumprir o destino exemplar de espírito. Com isto, a existência deixa de ter sentido, transformando-se num caminhar errante. O corpo passa a ser visto apenas como um invólucro protetor, continente da alma, mas que não tem valor em si e que, por isso mesmo, pode ser desprezado ou condenado por conspurcar a alma, ao prendê-la ao mundo baixo do instinto. A cisão sígnica do homem leva-o, por conseguinte, a tentar compreender o mundo e as coisas de maneira similar: tudo é cindido, tudo é dual.

De modo oposto, no mundo da Natureza, as partes se harmonizam perfeitamente, porque, segundo Swedenborg, "todo mundo natural corresponde ao mundo espiritual, não somente o mundo natural em geral, mas também em cada pormenor" (1817, p. 334). Conclui-se que a Natureza é similar ao símbolo: as coisas visíveis são agregadas às coisas do mundo espiritual, ou melhor, são formas aptas a revelar o espírito, são as transfigurações do espírito. E, pelo fato de se constituírem como repositório do sagrado, têm um valor intrínseco que não pode ser desprezado. Para mostrar essa identidade entre todas as coisas da Natureza, Baudelaire serve-se de imagens antitéticas - "noite" e "claridade" - que se fundem, criando perfeita integração entre os mundos sonoro ("ecos") e o visual ("tenebrosa").

Essa profunda unidade adquire qualidade visual e sonora, manifestando-se como algo sensível. O recurso à sinestesia torna-se absolutamente necessário - as sensações desdobram-se em imagens poéticas: os perfumes são frescos como carnes de crianças,
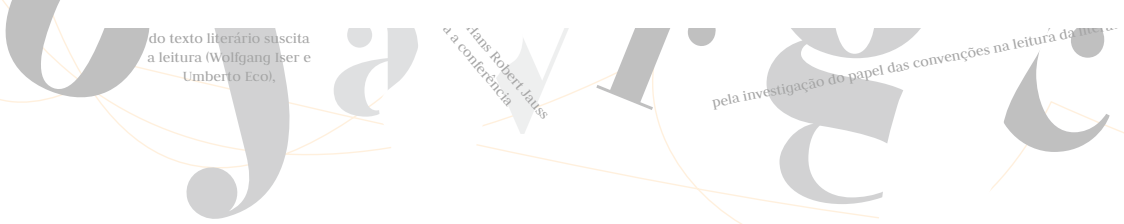
lembram a doçura dos oboés e evocam o verdor de pradarias. Tais sensações, contudo, não se oferecem de maneira sucessiva, mas em bloco, como se o perfume que dá início ao processo sinestésico despertasse, em conjunto, os demais sentidos. Assim, enquanto, no homem, devido ao uso da Razão, as sensações são separadas uma em relação às outras, na Natureza, tudo o que existe está integrado, e uma coisa corresponde à outra, de modo natural.

A terceira estrofe do poema revela-se como o fim de um ritual iniciático que teve início no segundo terceto. Como num templo, em que o perfume das especiarias serve para elevar o espírito até Deus, de maneira idêntica, as essências raras - o âmbar, o almíscar, o benjoim e o incenso, "tendo a expansão das coisas infinitas [...], cantam os transportes do espírito e dos sentidos". Ou seja, sob o influxo de um perfume, o homem vê despertarem nele os demais sentidos, que o conduzem ao paraíso das correspondências. Os diversos compartimentos do corpo e mesmo o corpo e a alma se correspondem, pois, em realidade, tal essência não só desperta imagens concretas (carnes de crianças, o verdor das pradarias), como também imagens abstratas: as sensações de corrupção, riqueza e triunfo.

Mas por que o início do processo se dá através do estímulo oloroso? O olfato é o menos intelectualizado e o mais primitivo dos sentidos, daí sua importância extraordinária para os animais e para os silvícolas, ao passo que, para o homem civilizado, tem relativa importância, principalmente se considerarmos o homem das grandes cidades que o vem atrofiando. O percurso imaginado por Baudelaire compreende o olfato, o tato, o gosto, a audição, a visão (o mais intelectual órgão dos sentidos) e, em seguida, as faculdades espirituais. Parte-se do mais primitivo dos sentidos, passa-se pelo mais intelectualizado e chega-se finalmente ao mundo dos valores espirituais. O processo completo subentende a integração plena das partes do corpo físico, de modo que este forme um organismo harmonioso, em que tudo se corresponde e, em seguida, a integração do físico e do espírito. O resultado é o ser visto na plenitude do corpo e do espírito, pronto a entender a linguagem da Natureza, que possui um corpo e uma alma associados.

O que Baudelaire realiza em “Correspondances” é nada mais, nada menos que um esforço poético para recuperar uma linguagem primitiva, em que o signo é agregado à coisa, pois “as correspondências são a época da recordação - não uma época histórica, mas uma época da pré-história" (BENJAMIN, 1973, p. 141). Essa linguagem imaginada por Baudelaire perde sua característica de instrumento, porque não visa à "comunicação". Pelo contrário, visa a expandir-se dentro dela própria, invadindo o terreno de outras linguagens, provocando a interação de diferentes códigos ou de diferentes tipos de artes, como a literatura, a música e a pintura.

Tal linguagem é mais sugestiva que precisa, adquirindo a capacidade de despertar no leitor sensações das mais diversas e não um único e previsível significado. O que se percebe é que Baudelaire cumpre aqui, no plano da linguagem, aquele que seria o desiderato dos grandes simbolistas: sugerir um mundo misterioso, por meio de uma expressão que necessitasse de uma leitura decifratória. Essa linguagem voltada para si e que tem grande poder de evocação, evidente em sua capacidade de despertar uma amálgama de sensações, prima pela alusividade, pela capacidade evocatória. Conclui-se que "Corres"
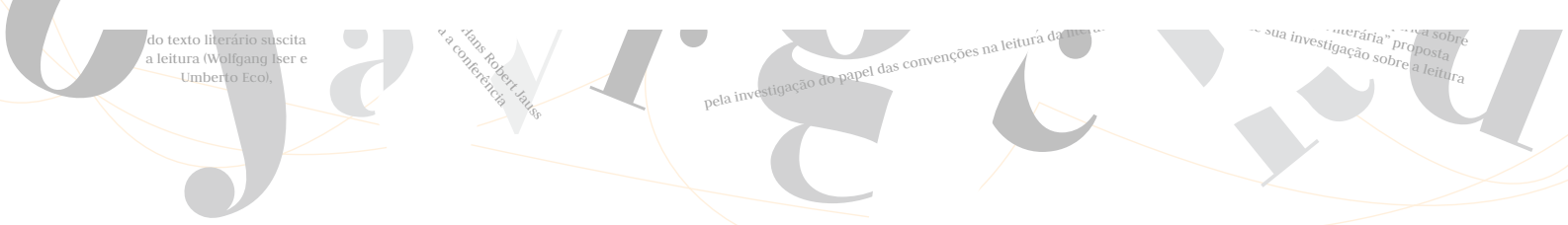
pondances", mais do que a afirmação de uma experiência mística, é a afirmação soberana da importância da linguagem, que recupera sua função essencial, a de revelar o sentido misterioso do mundo, do Universo. Ora, esse "sentido misterioso" não é nada mais que a perfeita integração do homem com a Natureza, através da experiência estética.

\section{Referências Bibliográficas}

BALAKIAN, Ana. El movimiento simbolista. Madrid: Guadarrama, 1969.

BALZAC, Honoré de. Les lys dans la vallée, La comédie humaine. Paris: Seuil, 1966, vol. VI. BAUDELAIRE, Charles. Les fleurs du mal. Paris: Garnier, 1961.

Curiosités esthétiques, l'art romantique et autres oeuvres critiques. Paris: Garnier, 1962. BENJAMIN, Walter. A lyric poet in the age of high capitalism. London: New Left Books, 1973. CHATEAUBRIAND, François-René de. "De la nature du mysthére". In: Beaux arts et littérature, 3a parte, Livre 2ㅇ, Ch. VIII, Le génie du Christianisme. Paris: Calman Lévy, 1885. DUFRENNE, Mikel. O poético. Trad. bras., Porto Alegre: Globo, 1969.

EMERSON, Ralph Waldo. The selected writings. New York: Randon House, 1968.

MANSELL JONES, P. "Swedenborg, Baudelaire and their intermediaries". In: The background of modern French poetry. Cambridge: University Press, 1951.

LAMARTINE, Alphonse de. Méditations poétiques, oeuvres poétiques complètes de Lamartine. Paris: Gallimard, 1963.

LÉVI, Eliphas. “Les correspondances”. In: BENICHOU, Paul. Le temps des prophètes. Paris: Gallimard, 1977.

NERVAL, Gerard de. Les chimères. London: The Athlone Press, 1973.

PAZ, Octavio. Os filhos do barro. Rio de Janeiro: Nova Fronteira, 1984.

POE, Edgar Allan. Complete tales and poems. New York: The Modern Library, 1938.

SAINT MARTIN, Louis Claude de. Tableau nature. Paris: Ed. du Griffon d'or,1946.

SWEDENBORG, Emmanuel. A treatise concerning Heaven and its Wonders, and also Concerning Hell. London: E. Hodson, 1817.

ArTigo ReCEBIDO EM: 22 ago. 2012

ArTigo ACEITO EM: 12 set. 2012

ReFERÊNCIA ELETRÔNICA: GOMES, Álvaro Cardoso. Baudelaire e a linguagem das correspondências. Revista Criação \& Crítica, n. 9, p. 128-139, nov. 2012. Disponível em: < http://www.revistas.usp.br/criacaoecritica>. Acesso em dd mmm aaaa. 